\title{
CARACTERIZAÇÃO DO FRUTO DE AMEIXA SILVESTRE (Ximenia americana L.) ${ }^{1}$
}

\author{
GEOMAR GALDINO DA SILVA ${ }^{2}$, PAHLEVI AUGUSTO DE SOUZA ${ }^{3}$, PATRÍCIALÍGIA DANTAS DE MORAIS ${ }^{4}$, \\ ELIZÂNGELA CABRAL DOS SANTOS ${ }^{5}$, RENATADAMASCENO MOURA ${ }^{6}$, JOSIVAN BARBOSA MENEZES $^{7}$
}

RESUMO - A Caatinga nordestina apresenta diversificada riqueza em espécies vegetais. No entanto, a potencialidade dessas espécies como fonte de nutrientes importantes para dieta humana ainda é muito pouco conhecida. Dentre estas espécies, encontra-se a ameixa silvestre (Ximenia americana L.). O presente trabalho teve como objetivo caracterizar os frutos da ameixa silvestre em dois estádios de maturação. Os frutos foram colhidos na Caatinga próxima ao município de Mossoró-RN, em dois estádios de maturação, verde (casca verde) e maduro (casca amarela), sendo 90 frutos para cada estádio. Para a caracterização do fruto, realizaram-se as seguintes análises: massa fresca, comprimentos longitudinal e transversal, rendimento de polpa, vitamina C, sólidos solúveis (SS), acidez titulável (AT), pH e relação SS/AT. Adotou-se o delineamento inteiramente casualizado, com dois tratamentos e seis repetições de 15 frutos para cada parcela. O fruto da ameixa silvestre é de formato arredondado, suculento e apresenta uma única semente tipo amêndoa. Considerando a polpa, ocorre mudança de coloração, passando da cor verde para a amarela, à medida que o fruto amadurece. Este fruto é considerado rica fonte de vitamina $\mathrm{C}$ que se encontra naturalmente na Caatinga nordestina, assim como um fruto com elevados teores de sólidos solúveis e acidez.

Palavras chaves: Ximenia americana L., vitamina C, Caatinga.

\section{WILD PLUM FRUIT CHARACTERIZATION (Ximenia americana L.)}

\begin{abstract}
The Brazilian Caatinga vegetation presents a large variety of vegetal species. However, the potentiality of these species as an important source of nutrients for the human diet is still not so known. Among these species, there is the wild plum (Ximenia americana L.). The present work aimed to characterize the fruits of the wild plum in two ripening stages. The fruits were harvested in the Brazilian Caatinga vegetation next to the Mossoró-RN city, in two ripening stages, green (green rind) and ripe (yellow rind), being 90 fruits for each stage. For the fruit characterization, the following analyses were done: fresh mass, longitudinal and transversal lengths, pulp yield, vitamin C, soluble solids (SS), titritable acidity (TA), $\mathrm{pH}$ and ratio SS/TA. The completely randomized design was used with two treatments and six replications of 15 fruits for each part. The wild plum fruit has a round shape, succulent and presents only seed of almond type. Considering the pulp, coloration change occurs, changing from green to yellow color, as the fruit becomes ripe. This fruit is considered rich vitamin $\mathrm{C}$ source that can naturally be found in the Brazilian northeastern region, as well as a fruit with high contents of soluble solid and acidity.
\end{abstract}

Index Terms: Ximenia americana L., vitamin C, Brazilian Caatinga vegetation.

\section{INTRODUÇÃO}

É grande o manancial de recursos genéticos autóctones existentes no Brasil, capaz de assegurar o uso sustentável do potencial biótico e abiótico de forma vantajosa, com o emprego consciente do capital intelectual. Trata-se de um País que ostenta os cinco principais biomas existentes em seus 851 milhões de hectares, o quinto maior em extensão do globo terrestre, onde, somente para plantas, apresenta um montante de 55 mil espécies, muitas delas endêmicas do País, correspondendo acerca de $21 \%$ do total mundial catalogado. Isso eleva sobremaneira a responsabilidade nacional pela manutenção e uso sustentável desses recursos doados pela natureza, principalmente para evitar a erosão genética ou mesmo a extinção de espécies que levaram séculos para serem criadas e disponibilizadas para a população brasileira (Villela-Morales \& Valois, 2000).

A Caatinga nordestina, sendo este um bioma e classificado por Giacomitti (1993) como um dos centros de diversidade 6 $\mathrm{NE}$ /Caatinga, apresenta diversificada riqueza em espécies vegetais. No entanto, a potencialidade dessas espécies como fonte de nutrientes importante para dieta humana ainda é muito pouco conhecida. Ainda existem muitas populações de plantas da caatinga não estudadas. Em função do desconhecimento, muito pouco de seus benefícios são aproveitados pelo homem.

Dentre estas espécies, encontra-se a ameixa silvestre (Ximenia americana L.), pertencente à família Olacaceae. Popularmente conhecida por ameixa-do-mato ou ameixa-brava e outros nomes, conforme o local em que está adaptada. De acordo com Fernadez \& Bezerra (1990), a ameixa silvestre faz parte do

(Trabalho 180-07). Recebido em: 26-07-2007. Aceito para publicação em: 01-02-2008

${ }^{2}$ Dr. em Agronomia. Universidade Federal Rural do Semi-Árido - UFERSA. E-mail: geomargaldino@yahoo.com.br. Mossoró/RN, CP 137.

${ }^{3}$ Dr. em Agronomia. Universidade Federal de Viçosa - UFV. E-mail: pahlevi10@hotmail.com.

${ }^{4}$ Dra. Sc., em Fisiologia Vegetal. Universidade Federal Rural do Semi-Árido - UFERSA. E-mail: plmorais@hotmail.com.

${ }_{5}^{5}$ Aluna de Doutorado - Universidade Federal Rural do Semi-Árido - UFERSA.

${ }^{6}$ Aluna de Mestrado - Universidade Federal Rural do Semi-Árido - UFERSA. E-mail: renata_raissa@yahoo.com.br.

${ }^{7}$ Dr. em Ciências dos Alimentos. Universidade Federal Rural do Semi-Árido - UFERSA. E-mail: reitor@ufersa.edu.br. 
extrato arbustivo-arbóreo da Caatinga, figurando como uma das principais espécies. No período seco, quando a maioria das espécies da Caatinga perde as folhas, essa planta destaca-se por apresentar-se com as folhas totalmente verdes, o que caracteriza uma planta resistente à seca. O período de frutificação é muito curto e concentra-se nos meses de dezembro a janeiro.

O fruto da ameixa silvestre é uma baga e, apesar de não ser considerada fruta comercial, é comestível. Franco \& Barros (2006), em estudos de localização e utilização de espécies de ervas medicinais presentes em uma determinada região do Piauí, verificaram que essa é uma espécie bastante utilizada no combate às infecções, ferimentos e falta de ar. Entretanto, não existem estudos acerca da importância dos frutos dessa espécie como fonte de nutriente para população.

As fruteiras nativas estão sendo estudadas em suas diversas características como: medicinais (juá, tamarindo); produção de frutas (caju, pitanga, Cajá, umbu, pitomba); antioxidantes (tamarindo, cajuí).

O presente trabalho teve como objetivo caracterizar os frutos da ameixa silvestre em dois estádios de maturação.

\section{MATERIAL E MÉTODOS}

Foram colhidos frutos de ameixa silvestre em populações de plantas que se encontram de forma espontâneas e dispersas na Caatinga, localizadas próximo ao município de Mossoró-RN, situado a aproximadamente $18 \mathrm{~m}$ de altitude, apresentando como coordenadas geográficas $5^{\circ} 11^{\prime}$ de latitude sul e $37^{\circ} 20^{\prime}$ de longitude oeste do meridiano de Greenwich. Segundo classificação de Köppen, o clima dessa região é do tipo BSwh', caracterizado como quente e seco, com precipitação pluviométrica média de $600 \mathrm{~mm}$, temperaturas mínima e máxima de $29^{\circ} \mathrm{Ce} 33^{\circ} \mathrm{C}$, respectivamente.

Os frutos foram colhidos diretamente na copa da planta, em dois estádios de maturação aparentes, verde (casca verde) e maduro (casca amarela), sendo 90 frutos para cada estádio. Posteriormente, foram conduzidos ao Laboratório de Agricultura Irrigada na Universidade Federal Rural do Semi-Árido-UFERSA, em Mossoró-RN, onde foram realizadas as análises.

No laboratório, os frutos foram pesados em balança semianalítica e medidos os comprimentos longitudinal e transversal com o auxílio de um paquímetro. No caso das avaliações químicas, foram realizados a retirada da casca e o despolpamento do fruto. Em seguida, a polpa foi homogeneizada em gral e, a partir desta, procederam-se as análises.

Para determinação de vitamina $\mathrm{C}$, foi utilizada a metodologia proposta por Strohecker \& Henning (1967). Pesaramse 5,0 g de polpa, diluindo-se para $100 \mathrm{~mL}$ de ácido oxálico. Posteriormente, retiraram-se $5,0 \mathrm{~mL}$ do extrato, adicionando-se $50 \mathrm{~mL}$ de água destilada e realizando a titulação com solução de Tilman. Os teores de sólidos solúveis (SS) foi determinado tomando-se $1,0 \mathrm{~g}$ de polpa e diluindo em $10 \mathrm{~mL}$ de água destilada e filtrado. A leitura foi realizada com o auxílio de um refratômetro digital, modelo PR-100 Pallete Atago, de acordo com Association of Official Analytical Chemists (2002). Para a determinação da acidez titulável (AT), pesou-se 1,0 g de polpa, diluindo-se para
$50 \mathrm{~mL}$ de água destilada e procedeu-se a titulação da amostra com solução de $\mathrm{NaOH} 0,1 \mathrm{~N}$, conforme metodologia do Instituto Adolfo Lutz (1985). O pH foi determinado de 1,0 g de polpa diluído em $10 \mathrm{~mL}$ de água destilada, por meio de um potenciômetro digital, modelo $\mathrm{pH}$ Meter Tec-2, conforme metodologia preconizada pelo Instituto Adolfo Lutz (1985). Determinou-se também a relação entre os sólidos solúveis e a acidez titulável (SS/AT).

Adotou-se o delineamento inteiramente casualizado, os tratamentos foram estádios de maturação (verde e maduro) com seis repetições compostas de quinze frutos cada, totalizando 180 frutos. Para a análise estatística, utilizou-se o programa computacional SISVAR 3.01. Realizou-se a anava, e as médias foram comparadas pelo teste de Tukey, a 5\% de probabilidade.

\section{RESULTADOS E DISCUSSÃO}

O fruto da ameixa silvestre é de formato arredondado, suculento e apresenta uma única semente tipo amêndoa. A casca do fruto é uma película fina, facilmente retirada, quando o fruto está maduro. Quando verde, tem coloração da casca verde, e quando maduro, a cor da casca torna-se amarela. Considerando a polpa, ocorre mudança de coloração, passando da cor verde para a amarela, à medida que o fruto amadurece. Também é perceptível um aroma característico nos frutos maduros.

Os frutos apresentam em média massa fresca de $4,8 \mathrm{~g}$ e comprimentos longitudinal e transversal de 1,89 e $1,88 \mathrm{~cm}$, respectivamente, ou seja, formato arredondado. Entre os frutos verdes e maduros, não houve diferença significativa para essas variáveis (Tabela 1), constatando que os frutos verdes estavam fisiologicamente desenvolvidos, porém ainda imaturos.

Pelos resultados encontrados, o fruto da ameixa silvestre é fonte rica de vitamina $\mathrm{C}$, atingindo em média $215,12 \mathrm{mg} .100 \mathrm{~g}^{-1}$ de polpa, sendo que o fruto verde apresentou teor $28,74 \%$ maior quando comparado com o maduro (Tabela 2). Dentre as espécies tradicionalmente cultivadas, com exceção da acerola com 1.800 mg.100 g ${ }^{-1}$ (Alves, 1993) e do camucamuzeiro $3.500 \mathrm{mg} .100 \mathrm{~g}^{-1}$ (Silva et al., 2006), este fruto apresenta teor de vitamina $\mathrm{C}$ superior às outras espécies, dentre as quais: melão, 10 a $30,00 \mathrm{mg} .100 \mathrm{~g}^{-1}$ (Menezes, 1996; Souza, 2006); mamão, 103 a 119 mg.100 g-1 (Bicalho, 1998); caju, 162 a $182 \mathrm{mg} 100 \mathrm{~g} \mathrm{~g}^{-1}$ (Hafle, 2000); abacaxi cv. Pérola, 50,6 mg.100 g ${ }^{-1}$ (Santana \& Medina, 2000); umbu-cajá, 12,9 a $18,35 \mathrm{mg} .100 \mathrm{~g} \mathrm{~g}^{-1}$ (Lima et al., 2002) e jabuticaba, 15,3 a $24,67 \mathrm{mg} .100 \mathrm{~g}^{-1}$ (Oliveira et al., 2003). O ácido ascórbico (vitamina C) não é sintetizado pelo organismo humano, o que torna indispensável sua ingestão mediante dieta, sendo as frutas consumidas preferencialmente in natura, as principais fontes dessa vitamina (Chitarra \& Chitarra, 2005).

A disponibilidade de frutos ricos em vitamina $C$ é importante no tocante à prevenção e manifestação de doenças, tornando o mesmo um dos componentes nutricionais mais importante, sendo utilizado como índice de qualidade dos alimentos.

Houve diferença significativa nos teores de SS, tendo o fruto maduro apresentado $18,88 \%$ de sólidos solúveis a mais quando comparado com o fruto verde (Tabela 2). Esse acúmulo 
de SS durante o processo de amadurecimento, na maioria dos frutos, é ocasionado pela degradação de amido. É importante destacar que esse fruto tem alto teor de SS, com média de $24,35 \%$, bem superior a outros frutos comercializados, como o melão, abacaxi, caju, mamão e manga.

Houve diferença significativa na acidez entre o fruto verde e o maduro; por outro lado, não houve diferença quanto ao $\mathrm{pH}$ (Tabela 2). Este fato ocorre em fruto devido a sua alta capacidade tamponante. A acidez apresentou uma redução de 14,44\% durante o processo de amadurecimento do fruto. Entretanto, esse fruto apresentou elevada acidez quando comparado com outros frutos, tais como abacaxi (Santana \& Medina, 2000), umbu-cajá (Lima et al., 2002) e jabuticaba (Oliveira et al., 2003).

A relação SS/AT foi baixa, pois, apesar do alto conteúdo de SS, a acidez deste fruto é alta. No fruto maduro, essa relação foi maior que no fruto verde (Tabela 2). Também foi observado que o fruto verde tem sabor adstringente, certamente devido à presença de taninos.

$\mathrm{Na}$ Tabela 3, encontram-se as porcentagem dos componentes dos frutos. Pode-se observar que o rendimento de polpa não é muito alto, já que sua semente representa $20,71 \%$ do fruto.

TABELA 1 - Massa fresca (g), comprimentos longitudinal e transversal $(\mathrm{cm})$ da ameixa silvestre colhidas nos estádios de maturação verde e maduro.

\begin{tabular}{lccc}
\hline \multirow{2}{*}{ Estádio de maturação } & Massa fresca & \multicolumn{2}{c}{ Características físicas } \\
\cline { 2 - 4 } & & longitudinal & $\begin{array}{c}\text { Comprimento } \\
\text { transversal }\end{array}$ \\
\hline Verde & $4,63 \mathrm{a}$ & $1,93 \mathrm{a}$ & $1,96 \mathrm{a}$ \\
Maduro & $4,96 \mathrm{a}$ & $1,85 \mathrm{a}$ & $1,85 \mathrm{a}$ \\
\hline Média geral & 4,8 & 1,89 & 1,88 \\
C.V (\%) & 8,19 & 4,51 & 4,32 \\
\hline
\end{tabular}

* Médias seguidas de mesma letra na coluna não diferem entre si, pelo teste de Tukey, a $5 \%$ de probabilidade.

TABELA 2 - Teores de vitamina C (mg de ácido ascórbico. 100 $\mathrm{g}^{-1}$ de polpa); sólidos solúveis (SS); acidez titulável (AT, \% ácido cítrico); pH; e relação sólidos solúveis/acidez da ameixa silvestre colhida em dois estádios de maturação.

\begin{tabular}{|c|c|c|c|c|c|}
\hline \multirow[b]{2}{*}{ Estádio de maturação } & \multicolumn{5}{|c|}{ Características químicas } \\
\hline & Vitamina C & SS $\left({ }^{\circ}\right.$ Brix $)$ & $\begin{array}{l}\text { AT(\% ácido } \\
\text { cítrico) }\end{array}$ & $\mathrm{pH}$ & SS/AT \\
\hline Verde & $251,21 \mathrm{a}$ & $22,25 \mathrm{~b}$ & $4,85 \mathrm{a}$ & $2,52 \mathrm{a}$ & $4,59 \mathrm{~b}$ \\
\hline Maduro & $179,02 \mathrm{~b}$ & $26,45 \mathrm{a}$ & $4,15 b$ & $2,68 \mathrm{a}$ & $6,39 \mathrm{a}$ \\
\hline Média geral & 215,12 & 24,35 & 4,59 & 2,6 & 5,49 \\
\hline CV $(\%)$ & 8,73 & 6,26 & 5,09 & 11,17 & 6,49 \\
\hline
\end{tabular}

*Médias seguidas de mesma letra na coluna não diferem entre si, pelo teste de Tukey, a $5 \%$ de probabilidade.
TABELA3 - Composição das partes da ameixa silvestre colhida madura.

\begin{tabular}{lc}
\hline Parte do fruto & Percentagem* \\
\hline Polpa & 63,52 \\
Casca & 15,77 \\
Semente & 20,71 \\
\hline *Média de 15 frutos &
\end{tabular}

\section{CONCLUSÕES}

O fruto da ameixa silvestre possui altos teores de vitamina C, podendo ser considerada uma boa fonte dessa vitamina, além de possuir elevados teores de sólidos solúveis e acidez.

\section{REFERÊNCIAS}

ASSOCIATION OF OFFICIAL ANALYTICAL CHEMISTRY. Official methods of analysis of the Association of Official Analytical Chemistry. $17^{\text {th }}$ ed. Washington: AOAC, 2002, 1115 p.

ALVES, R. E. Acerola (Malpiphia emarginata D. C.) fisiologia da maturação e armazenamento refrigerado sob atmosfera ambiente e modificada. 1993. 99 f. Dissertação (Mestrado em Fisiologia Vegetal) - Universidade Federal de Lavras, Lavras, 1993.

BICALHO, U. O. Vida útil pós-colheita de mamão submetido a tratamento com cálcio e filme de PVC. 1998. 145 f. Tese (Doutorado em Ciências dos Alimentos) - Universidade Federal de Lavras, Lavras, 1998.

CHITARRA, M. I. F.; CHITARRA, A. B. Pós-colheita de frutos e hortaliças: fisiologia e manuseio. 2.ed. ver. Lavras: UFLA, 2005. $785 \mathrm{p}$.

FRANCO, E.A.P.; BARROS, R.F.M. Uso e diversificação de plantas medicinais no quilombo olho d'água dos Pires, Esperantina, Piauí. Revista Brasileira de Plantas Medicinais, Botucatu, v.8, n.9, p.78-88, 2006.

FERNANDEZ, A.; BEZERRA, P. Estudo fitogeográfico do Brasil. Fortaleza: Stylus comunicações, 1990.

GIACOMITTI, D. C. Recursos genéticos de fruteira nativas do Brasil. In: SIMPOSIO NACIONAL DE RECURSOS GENETICOS DE FRUTEIRAS NATIVAS, 1., 1993, Cruz das Almas, BA. Anais...Cruz da Almas: EMBRAPA-CNFMF, 1993.p.13-27

HAFLE, O. M. Conservação pós-colheita de pedúnculo de cajueiro anão "CCP-76" submetido à aplicação de cálcio. 2000. 49 f. Dissertação (Mestrado em Fitotecnia) - Escola Superior de Agricultura de Mossoró, Mossoró, 2000. 
INSTITUTO ADOLFO LUTZ. Normas analíticas, métodos químicos e físicos de alimentos. 3.ed. São Paulo: IAL, 1985. v. 1, $553 \mathrm{p}$.

LIMA, E. D. P. A.; LIMA, C. A. A.; ALDRIGUE, M. L.; GONDIN, P. J. S. Caracterização física e química dos frutos de umbu-cajá (Spondias spp) em cinco estádios de maturação, da polpa congelada e néctar. Revista Brasileira de Fruticultura, Jaboticabal. v. 24, n. 2, p.338-343, 2002.

MENEZES, J. B. Qualidade pós-colheita do melão tipo Gália durante a maturação e o armazenamento. 1996. 157 f. Tese (Doutorado em Ciências dos Alimentos) - Universidade Federal de Lavras, Lavras, 1996.

OLIVEIRA, A. L.; BRUNINI, M. A.; SALANDINI, C. A. R.; BAZZO, F. R. Caracterização tecnológica de jaboticabas "Sbará" provenientes de diferentes regiões de cultivo. Revista Brasileira de Fruticultura, Jaboticabal. v. 25, n. 3, p. $397-400,2003$.
SANTANA, F. F.; MEDINA, V. M. Alterações bioquímicas durante o desenvolvimento do fruto do abacaxizeiro "Pérola". Revista Brasileira de Fruticultura, Jaboticabal. v. 22, n. especial, p. 53-56, 2000.

SILVA, E. G.; RIBEIRO, S. I.; RIBEIRO, N. S. V. Caracterização morfológica de camucamuzeiro cultivar solimões. In: CONGRESSOBRASILEIRODEFRUTICULTURA, 19., 2006, Cabo Frio. Anais... Cabo Frio: CBF, 2006. p. 443.

SOUZA, P. A. Conservação pós-colheita de melão Charentais tratado com 1-MCP e armazenado sob refrigeração e atmosfera modificada. 2006. Tese (Doutorado em Fitotecnia) - Universidade Federal de Viçosa, Viçosa, 2006.

STROHECKER, R.; HENINING, H. M. Análisis de vitaminas: métodos comprobrados. Madrid: Paz Montalvo, 1967. 42 p.

VILELA-MORALES, E. A.; VALOIS, A. C. C. Recursos genéticos vegetais autóctones e seus usos no desenvolvimento sustentável. Cadernos de Ciência \& Tecnologia, Brasília, v.17, n.2, p.11-42, 2000 . 